since he was an important policy actor. He had expressed his interest in participating, offered to share his research and given his consent (conditional) to audio recording. His refusal was only to signing a document which, if revealed, could affect his reputation in government circles and lead to hostility from his former colleagues.

The proposed HPSR ethics framework requires researchers to consider the potential institutional reputational risks to participants and warn potential participants of this risk (2). Many retired officials get work assignments and deputations from the government. In this case, if the official's participation in the research project became known, he could face hostility and stigma in official circles, and lose job opportunities.

In this case, the researcher's dilemma was twofold:

- If she decided to engage with the participant without insisting on written consent, the research would be violating regulations.

- If she decided to forego his participation, she would miss gathering important insights on policy issues in her research subject.

\section{Questions raised by the case}

1. Could the researcher have conducted ethical research without doing the project injustice?

2. What alternative measures could have been suggested by the IEC in this case?

3. Does the requirement of signed informed consent uphold participants' autonomy?

4. Should the concept of "risk" be redefined in the context of public health research?

\section{References}

1. Alliance for Health Systems and Policy Research. Briefing Note 1. What is health policy and systems research and why does it matter? Geneva: Alliance HPSR, WHO; 2007 Jun[cited 2019 Dec 12]. Available from: https://www.gov.uk/dfid-research-outputs/what-is-health-policy-andsystems-research-and-why-does-it-matter

2. Luyckx VA, Biller-Andorno N, Saxena A, Tran NT. Health policy and systems research:towards a better understanding and review of ethical issues. BMJ Glob Health. 2017;2:e000314.

\title{
Between participation and signature: a response to "Autonomy and risk in HPSR studies"
}

\section{RAKHI GHOSHAL}

Keywords: Autonomy, risk, health policy and systems research, informed consent, written consent, waiver of consent, participation in HSPR

\section{A background}

Health Policy and Systems Research (HPSR) is defined as the "production of new knowledge to improve how societies organise themselves to achieve health goals" (1: $p$ 4); the focus of HPSR studies is on generating, using and disseminating research to strengthen health systems, particularly in lowand middle-income countries. There has been an increasing focus on defining HPSR clearly and on its ethical components and challenges, especially as this domain, is fundamentally different from biomedical /clinical research. One of the imperatives of HPSR is the "co-production of knowledge" (1: $p$ 4) by the researcher, the communities involved, and healthcare providers; and this calls for shared responsibility

Author: Rakhi Ghoshal (rakhi.ghoshal@gmail.com), CARE India, Patna, Bihar 800 013. INDIA.

To cite: Ghoshal R. Between participation and signature: a response to "Autonomy and risk in HPSR studies". Indian J Med Ethics. 2020 Jan-Mar; 5(1) NS:14-6 DOI: 10.20529/IJME.2020.011.

Peer Reviewers: Rakhal Gaitonde and an anonymous reviewer.

CIndian Journal of Medical Ethics 2020 and ownership, which is not an essential aspect of biomedical research

Our understanding of research ethics is challenged when the standards of biomedical research are applied to HPSR studies; especially when obtaining consent and protecting confidentiality become difficult. These aspects are exemplified in this case study (2), where the research participant, a senior level policy maker with the government, refused to give written consent even as he was willing to participate in the study. He did not feel confident about his identity remaining confidential once he had signed the informed consent sheet. His concern stemmed from the need to avoid a possible whistleblower image which could jeopardise his association with the government.

While what the senior policy maker had to share would be valuable for the study, the information could not be used by the researcher without a waiver of written informed consent from the IEC. The key issue here is whether informed consent is equal to written informed consent. The 2019 WHO Guidelines (1) say: "Researchers and RECs must proceed on the presumption that the informed consent of policy-makers, decision-makers and health providers in HPSR studies is required". However, with respect to obtaining the option of a consent waiver, the guidelines $(1: p$ 9) further clarify that:

"While the requirement for informed consent of patients in 
research is well accepted, it has been suggested that informed consent is not required from health providers, as they have a duty to participate in quality improvement research... This argument may extend to policy-makers and other decision-makers in HPSR. We consider that policy-makers, decision-makers and health providers have a prima facie ethical duty to seek to continually improve the delivery and outcome of health care."(1:p 19)

Against this background, the case raises a few specific questions:

\section{Could the researcher have conducted ethical research without doing the project injustice?}

Research that is conducted in accordance with the principles of research ethics - such as doing no harm, ensuring privacy and confidentiality, giving proper and complete information and documenting consent (or refusal), and sharing data back with the community - constitutes ethical research. In this research context, a component of ethical research, giving proper and complete information and documenting consent, is challenging because the participant has given oral consent and is clearly acting autonomously, as he is taking charge of the audio recording process. Citing the social value of this research and the risk of breaking confidentiality in interviewing top level senior policy makers, the researcher could have argued for a waiver (1: p 20) with the ethics committee. If the waiver had been refused by the IEC the researcher could have proceeded by taking certain inputs from the policy maker regarding the functionality and challenges that shaped the policy prescriptions made by the regulatory agency. These could subsequently have been substantiated through other potential respondents in the policy makers network, or through publicly available records, so that in citing these the particular policy maker could be avoid being named. These steps could help ensure justice for the project without violating the confidentiality requirements of the policy maker.

\section{What alternative measures could have been suggested by the IEC in this case?}

Having acknowledged the challenges of this particular study, the IEC could have waived the need for written consent in those cases where the prospective respondent's participation was critical to a study, but written consent was not obtainable. In such cases, the researcher would need to share the details with the IEC of why the waiver clause was used. This explanatory document would need to include details on:

- Why a written waiver is being sought: the nature of the power differential between the researcher, who in this case is a junior with no standing in the bureaucratic hierarchy, while the participant is a senior bureaucrat. Hence, there is little scope of the latter's willingness to participate in the study being unduly exploited.

- What precautions are being taken to ensure voluntary participation: explaining how the researcher would ensure that all relevant information about the research has been shared with the participant; along with the submission of an undertaking that the participant shared all information voluntarily and with the knowledge that it would be used only for the purposes of the study.

- Why the participant can be assumed to have understood the nature of research and the assurance of confidentiality, given his/her educational and occupational background.

\section{Does the requirement of signed informed consent uphold participants' autonomy?}

Ensuring the consent of a study participant is non-negotiable for research ethics, a core component of the ethical principle of respect for persons. However, consent is meaningful only when it is based on clear, transparent information, and the obligation of relevant and adequate disclosure rests on the researcher. The "signed" informed consent is more about the recording of the process and quality of consent for peers and the larger community, part of IEC requirements; the signature as document also serves as protection for the researcher.

In many research contexts, it is not uncommon for participants to be willing to participate in a study but resistant to signing the informed consent sheet. The act of signing implies a degree of finality, invoking a fear of disclosure - not just in the lesseducated and vulnerable populations, but also in the educated and powerful. In our case, the policy maker was' anxious about being labelled a whistleblower. However, notwithstanding the seniority of the bureaucrat and the express manifestation of his agency throughout the participation process (deciding on the terms), it is the ethical obligation of the researcher to address the anxieties of the participant. It is imperative that the researcher run through the participant information sheet, and confirm that the signed informed consent sheet would remain confidential with very restricted access, and the name of the participant would not be revealed under any circumstance.

The official consented to participate in the study and set the terms for proceeding with the interview; he was clearly not in any vulnerable position, inasmuch as we understand normative vulnerability in healthcare research. Nonetheless, he interpreted the process of documenting his consent as compromising his decision-making power, ie, his autonomy. While the mandate of the signed informed consent can at times compromise the participant's autonomy, given the value the process carries, waiving it cannot become normative in the specific challenges of HPSR studies. The waiver of written consent needs to be deliberated upon and calibrated in a robust manner. While the scope of waiver needs to be expanded, a corollary process of documenting cases when signed informed consent is not obtainable, needs to be developed.

\section{Should the concept of "risk" be redefined in the context of HPSR studies?}

Risk, in the context of biomedical/ clinical research, is defined as the aggregate harm a participant is potentially exposed to, which is weighed against the benefits of the research that accrue to him/her. This is premised on the understanding that except in specific cases, biomedical research entails a 
degree of harm, whether physical, psychological or social. The balancing of harm against benefit is the risk-benefit ratio, and a favourable risk-benefit ratio is a prime determining factor of whether a research study should be allowed to go ahead. However, this framework is challenged when it comes to HPSR studies, because, while the risks may accrue to one group, the benefit may accrue to another. Clinical equipoise is "traditionally defined as a state of genuine uncertainty on the relative value of two approaches being compared in a trial" (3). In HPSR studies, clinical equipoise is difficult to assess since the intervention is not about evaluating its efficacy, but to "analyse changes in policy, implementation or service delivery" (1: p 6). As "risk" is not clearly spelt out in HPSR studies, it gets interpreted along the lines of risk in biomedical research; but as the author of the above case study suggests, the concept of risk needs to be rearticulated for HPSR studies.

\section{References}

1. Alliance for Health Policy and Systems Research (WHO) and Global Health Ethics Unit (WHO). Ethical considerations for health policy and systems research. Geneva, WHO; 2019[cited 2020 Jan 26] Available from: https:// apps.who.int/iris/bitstream/handle/10665/330033/9789241516921eng.pdf?ua $=1$

2. Mohan M. Autonomy and risk in health policy and systems research. Indian J Med Ethics. 2020 Jan-Mar;5(1) NS:13-4. DOI: 10.20529/ IJME.2020.010

3. Rabinstein AA, Brinjikji W, Kallmes D F. Equipoise in clinical trials: Angst and progress. Circ Res. 2016 Sep 16; 119(7):798-800. DOI: 10.1161/ CIRCRESAHA.116.309594.

\section{Observation of unsafe medical practice during research in a healthcare- deprived area}

\section{BEVIN VIJAYAN}

Keywords: Unethical treatment, quacks, RMPs, reporting unethical treatment

\section{Background and context}

The health workforce in India is unevenly distributed within and across regions, with qualified practitioners more concentrated in urban areas (1). In rural and poor areas where there are no doctors, unqualified medical practitioners are the first point of contact for healthcare needs (1). These unqualified medical practitioners, also called Rural Medical Practitioners (RMP), practise western medicine without any formal training. They may hold certificates from organisations that are not recognised by regulatory authorities (2). RMPs work under doctors as helpers, observe their work, and then set up clinics or practise in areas where there are no doctors (3). They are described as quacks by the IMA and the Supreme Court of India. The IMA has been fighting to eliminate these providers from the system $(3,4)$.

An ethnographic ${ }^{1}$ study was done among a nomadic tribe in a rural district to understand their access to healthcare. The tribe lives in settlements called tandas (5). The nearest public health facility from this particular tanda is around $9 \mathrm{~km}$. Road connectivity to this public health facility is good, but there is

\footnotetext{
Author: Bevin Vijayan (bevinvinay@gmail.com), PhD Scholar, Achutha Menon Centre for Health Science Studies, Sree Chitra Tirunal Institute for Medical Sciences and Technology, Thiruvananthapuram, Kerala, 695011 INDIA.

To cite: Vijayan B. Observation of unsafe medical practice during research in a healthcare-deprived area. Indian J Med Ethics. 2020 Jan-Mar; 5(1) NS: 16-7. DOI:10.20529/IJME.2020.012.

CIndian Journal of Medical Ethics 2020
}

no public transport to reach the facility from the tanda. People have to rely on private vehicles. A few RMPs and Bachelor of Ayurveda Medicine and Surgery doctors live in a settlement about $3 \mathrm{~km}$ from the tanda. They provide services in their clinic and also visit the tanda whenever called. They are available on call even in the middle of the night.

\section{The case}

The researcher, who is undertaking an ethnographic study, visits the tanda regularly to observe and interview the people regarding their access to healthcare. Consent has been obtained from the village head and the elected representative to carry out this work. During one such visit, the researcher observes an old man being treated by an RMP for a head injury sustained by a fall. The RMP does not belong to the tanda but provides emergency services here and was called by the relatives. The RMP informs the family that the wound needs suturing to control bleeding. The researcher notes that the RMP instructs one of the relatives to bring a bowl of hot water and some old newspapers. The RMP then takes out a pair of gloves, cotton and suturing materials from plastic boxes in a compartment of his bag. The boxes do not seem to have been maintained in aseptic conditions. The RMP uses the cotton to clean the wound, asking the relatives to hold the old man's body and head in position. He sutures the wound without administering local anaesthetic or other pain medication. The researcher observes the old man writhing in pain throughout the procedure. After suturing, the RMP cuts the suture material off with a pair of scissors which he takes out from his bag.

After the procedure, the RMP instructs the relatives to clean the scissors, using the hot water provided, and asks them to dispose of the used cotton and gauze which was placed on 